\title{
RESEARCH
}

Open Access

\section{Bibliometric analysis of peer-reviewed literature on antimicrobial stewardship from 1990 to 2019}

Waleed M. Sweileh(1)

\begin{abstract}
Background: The World Health Organization recommended the implementation of antimicrobial stewardship (AMS) in the clinical settings to minimize the development and spread of antimicrobial resistance (AMR). The current study aimed to assess global research activity on AMS as one measure for efforts dedicated to contain AMR.

Method: A bibliometric method was applied using Scopus. A validated search query was implemented. Bibliometric indicators and mapping were generated. The study period was from 1990 to 2019. The search query utilized the keywords "antimicrobial stewardship" or "antibiotic stewardship" in the titles or abstracts. In addition, documents with the term "restrict" or "restriction" if used with the terms "antimicrobial" or "antibiotic" were retrieved.

Results: The search query returned 4402 documents. The keyword "antimicrobial stewardship" returned 2849 documents while the keyword "antibiotic stewardship" returned 1718 documents. The terms restrict/restriction and antimicrobial/antibiotics returned 209 documents. The number of publications and cumulative citations showed a steep and parallel increase in the last decade. The region of the Americas returned the most while the Eastern Mediterranean region returned the least. The United States $(n=1834,41.7 \%)$ ranked first. Main research themes in the retrieved literature were the (1) impact of AMS on hospital length stay, (2) role of pharmacists, and (3) development of resistance of various pathogens. Clostridium difficile $(n=94)$ and Staphylococcus aureus $(n=76)$ were among the most frequently encountered author keywords. The Infection Control and Hospital Epidemiology journal ranked first $(n=245$, $5.6 \%$, h-index $=134$ ) while documents published in the Clinical Infectious Diseases journal (h-index $=321$ ) received the highest number of citations per document (70.7). At the institutional level, the US Centers for Disease Prevention and Control $(n=93,2.1 \%)$ ranked first followed by the Imperial College London $(n=86,2.0 \%)$. The main funding sponsors were the National Institute of Health. Pfizer, Merck, and Bayer pharmaceutical companies played a key role in funding AMS research. International research collaboration between developed $(n=3693,83.9 \%)$ and developing countries $(n=759,17.2 \%)$.
\end{abstract}

Conclusion: The fight against AMR is a global responsibility and implementation of AMS need to be carried out across the globe. International research collaboration between developing and developed countries should be encouraged.

Keywords: Anti-microbial stewardship, Antimicrobial resistance, Infectious diseases, Outbreaks, Bibliometric analysis

Correspondence: waleedsweileh@yahoo.com

Department of Physiology, Pharmacology/Toxicology, Division of Biomedical Sciences, College of Medicine and Health Sciences, An-Najah National

University, Nablus, Palestine

(c) The Author(s). 2021 Open Access This article is licensed under a Creative Commons Attribution 4.0 International License, which permits use, sharing, adaptation, distribution and reproduction in any medium or format, as long as you give appropriate credit to the original author(s) and the source, provide a link to the Creative Commons licence, and indicate if changes were made. The images or other third party material in this article are included in the article's Creative Commons licence, unless indicated otherwise in a credit line to the material. If material is not included in the article's Creative Commons licence and your intended use is not permitted by statutory regulation or exceeds the permitted use, you will need to obtain permission directly from the copyright holder. To view a copy of this licence, visit http://creativecommons.org/licenses/by/4.0/. The Creative Commons Public Domain Dedication waiver (http://creativecommons.org/publicdomain/zero/1.0/) applies to the data made available in this article, unless otherwise stated in a credit line to the data. 


\section{Background}

Antimicrobial agents lose their activity with time because microbes, mostly on a genetic basis, develop resistance to medications [1]. Antimicrobial resistance (AMR) is accelerated upon misuse and overuse of antimicrobial agents [2]. Many reports from different parts of the world indicated a high prevalence of inappropriate or incorrect use of antibiotics both in hospitals and in primary healthcare centers [3-8]. The Global Action Plan (GAP) on AMR, endorsed by the World Health Organization (WHO) in 2015 , considered the optimization of antimicrobial use as one of the important strategic objectives that should be included in developing national action plans to combat AMR [9]. In 2017, the "Political Declaration of the HighLevel Meeting of the General Assembly on AMR" reaffirmed that the third goal in Sustainable Development Goals (SDGs) cannot be attained without tackling the problem of AMR [10]. In 2019, the WHO listed AMR as one of the top ten global health threats [11].

Antimicrobial Stewardship (AMS) has been defined as "the optimal selection, dosage, and duration of antimicrobial treatment that results in the best clinical outcome for the treatment or prevention of infection, with minimal toxicity to the patient and minimal impact on subsequent resistance." [12]. The AMS programs have three general goals: (1) deliver the optimum antimicrobial therapy, (2) minimize misuse and abuse of antimicrobial agents, and (3) minimize the development of antimicrobial resistance $[13,14]$. The AMS programs are important in hospital settings where AMR is high and poses a real threat to hospitalized patients [15-17]. In the past decade, reports on AMR in gram-negative bacteria has increased and calls for urgent action were made by international health organizations [18]. According to the United States Centers for Disease Control and Prevention (US CDC), each year in the U.S., at least 2.8 million people are infected with antibiotic-resistant bacteria or fungi, and more than 35,000 people die as a result [19]. The WHO has developed and published practical guidelines on how to optimize the use of antimicrobials by implementing AMS [20].

Research activity on Amiss an indicator of the extent of awareness of researchers and healthcare providers of the importance national and international health security given that the number of new effective antibiotics is limited and risks of serious infections is still valid. Research activity on AMS helps better future planning in the fight against AMR. Research activity, in general, reflects the commitment of governments and international health organizations in funding research related to important practical issues for the safety of human beings. The bibliometric analysis and data visualization have been widely used tools to measure and evaluate scientific research quantitatively and qualitatively $[21,22]$. At least
10 bibliometric studies on AMR have been published [23-27]. However, none was published on AMS. Gaining knowledge about the published literature on AMS is of high value since it shed light on the national contribution to this field. The bibliometric analysis provides information for comparative purposes among different countries [28]. Furthermore, bibliometric data provides information about research volume and activity of different institutions for better allocation of funding. There are several scientific databases including Web of Science, Scopus, PubMed, and Google Scholar that would bring out the scientific research metrics available in the literature. Scopus database owned by Elsevier is $100 \%$ inclusive of PubMed and included twice the number of journals indexed in the Web of Science [29].

The current study aimed to use the Scopus database, which is large and provide metric analytics, to shed light on the scientific publications on AMS. The analysis focused on describing the most productive journals, institutions, authors, citations, and countries, as well as the characteristics of the relevant documents.

\section{Methods}

\section{Database used}

The current study used bibliometric methodology for quantitative description of the literature on AMS published in peer-reviewed journals. Grey literature such as government reports and brochures were not included in the analysis. Data used in the current study were retrieved from Scopus database since it is the largest database [29] and commonly used in the bibliometric analysis [23, 30, 31]. In bibliometric studies, usually, one database is used because bibliometric indicators and literature mapping are difficult to perform on documents retrieved from different databases. Scopus is practically $100 \%$ inclusive of PubMed and has double the number of indexed journals compared to Web of Science [29]. Therefore, Scopus is considered comprehensive and inclusive of publications present in both PubMed and Web of Science.

\section{Search query}

The advanced search function was used in Scopus to allow for developing comprehensive search queries that include different Boolean operators. Before entering the search query, the authors did a literature review on articles about AMS to have a clear idea about all possible keywords used in AMS literature [32-39]. No previous bibliometric studies on AMS were previously published. Therefore, the search query was uniquely developed for the current study. The search query used in the current study utilized the keywords "antimicrobial stewardship" or "antibiotic stewardship (ABS)" in the titles or abstracts. This approach will retrieve the bulk of literature 
on AMS. However, there are certain publications in which the keywords AMS or ABS were not mentioned explicitly and therefore a second search scenario was added to the query. For example, the term "restrict" or "restriction" if used with the terms "antimicrobial" or "antibiotic" will retrieve certain documents on AMS. The full list of terms used in the second scenario included: preauthorization or pre-authorization or audit or feedback or stream-lining or streamlining or discontinuation or de-escalation or de-escalation or optimization or step-down or stepdown or education or program* or control or "quality assurance" or "decision support" or intervention or program or restrict*. The study period was from 1950 to 2019.

\section{Validation of the search query}

In the current study, the search query was validated using three criteria. The first criteria was the judgment of two external colleagues in the field of health sciences on 100 documents sent to them as an Endnote file. The reviewers had to judge on the presence of false-positive results. The principal investigator was the final judge in case of disagreement. The absence of false-positive results was used as an indicator of validity. The author kept fine-tuning the search query until the two reviewers gave feedback on the absence of false-positive results. The second criterion of validity was the relevancy of the top 20 journals to the topic of AMS. In the final search query, the top 20 active journals were mostly in the field of infections, antimicrobials, and health. The third criterion of validly was the comparison of the research output of the top ten active authors with the number of documents on AMS for the same authors present in their Scopus profile. For example, Pulcini, C. $(n=57$ documents), Srinivasan, A. ( $n=42$ documents), Goff, D. A (41 documents) and Newland, J. G (41 documents) while their Scopus profile indicated the following numbers 55 , 41, 41, and 41 respectively. Pearson correlation test between the retrieved numbers and the actual numbers of ten selected authors gave a significant, positive, and strong correlation $(p=0.002, r=0.945)$ suggesting a high validity of the search strategy.

\section{Data export and analysis}

The retrieved data was exported to Microsoft Excel for tabulation. The exported data included the type of documents, annual number of publications, author names, journals, countries, institutions, funding agencies, and number of citations. Only the top ten active authors, countries, journals, institutions, and funding agencies were listed. A linear graph was created to present the annual growth of publications. Bar chart graph was created to present the extent of research collaboration for active countries. The linear and bar chart graphs were created using Statistical Package for Social Sciences (BM SPSS Statistics for Windows, Version 24.0. Armonk, NY: IBM Corp.).

\section{Geographic distribution of the retrieved documents}

For geographic distribution of publications, the WHO classification of world regions was used: African region (AFRO), Region of the Americas (AMRO), South-East Asia Region (SEARO), European Region (EURO), the Eastern Mediterranean Region (EMRO), and Western Pacific Region (WPRO). The WHO classification was used because the WHO is in the front line for fighting AMR.

\section{International research collaboration}

Inter-country (international) versus intra-country (local) research collaboration for the top ten active countries was assessed. Furthermore, the research collaboration between the top ten active countries and developing countries with minimum research output of 10 documents was mapped. In the current study, the International Monetary Fund was used for the classification of countries [40].

\section{Network visualization maps}

The network visualization map of the most frequent author was created by VOSviewer program [41]. In the network visualization map, the node size is proportional to the number of occurrences while the distance between the terms measures the strength of the relation between the terms with closer distance implying a stronger relation.

\section{Results}

The keyword "antimicrobial stewardship" returned 2849 documents while the keyword "antibiotic stewardship" returned 1718 documents. The terms restrict/restriction and antimicrobial/antibiotics returned 209 documents. The overall search query returned 4402 documents.

The earliest retrieved literature on AMS started in 1996 with a review article published in the New Horizons: Science and Practice of Acute Medicine [42]. The article discussed the relationship between antibiotic restriction (stewardship) and the development of antibiotic resistance. The growth of publications on AMS remained low from 1996 to $2010(n=252,5.7 \%)$ followed by a steep increase from 2011 to 2019 ( $n=4150,94.3 \%)$. The number of publications in 2019 was 14 times higher than that in 2010. The retrieved documents have an h-index of 96 . Figure 1 shows an increasing trend in the annual number of publications and the number of cumulative citations during the study period. 


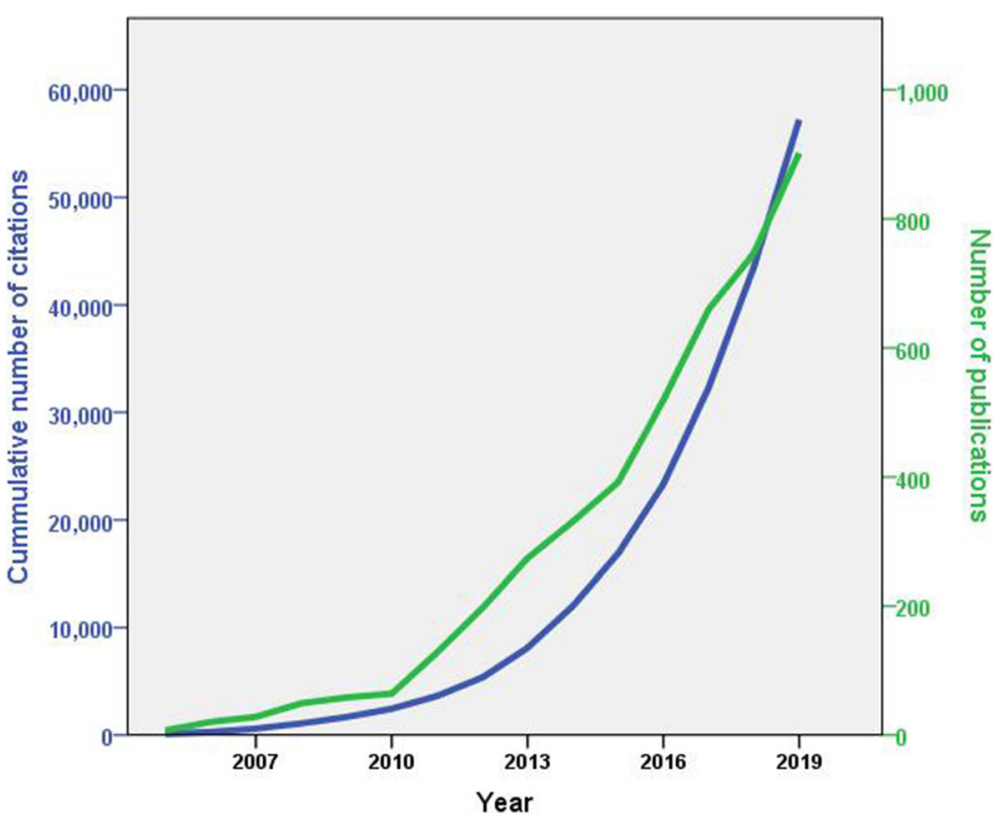

Fig. 1 Annual growth of publications and cumulative citations on AMS

The retrieved documents were mainly research articles $(n=3065,69.6 \%)$ and review articles $(n=853,19.4 \%)$. Most of the retrieved documents were published in English $(n=4155,94.4 \%)$. The remaining non-English documents were in German $(n=133,3.0 \%)$, French $(n=43,1.0 \%)$ or Spanish $(n=43,1.0 \%)$.
Network visualization (Fig. 2) of author keywords indicated that AMS, ABS, AMR, antibiotics, ABR, infection control, Clostridium difficile, urinary tract infection, procalcitonin, surveillance, pneumonia, MRSA, and pediatrics were most frequent. The terms in Fig. 2 were presented in Table 1 with their corresponding number of occurrences.

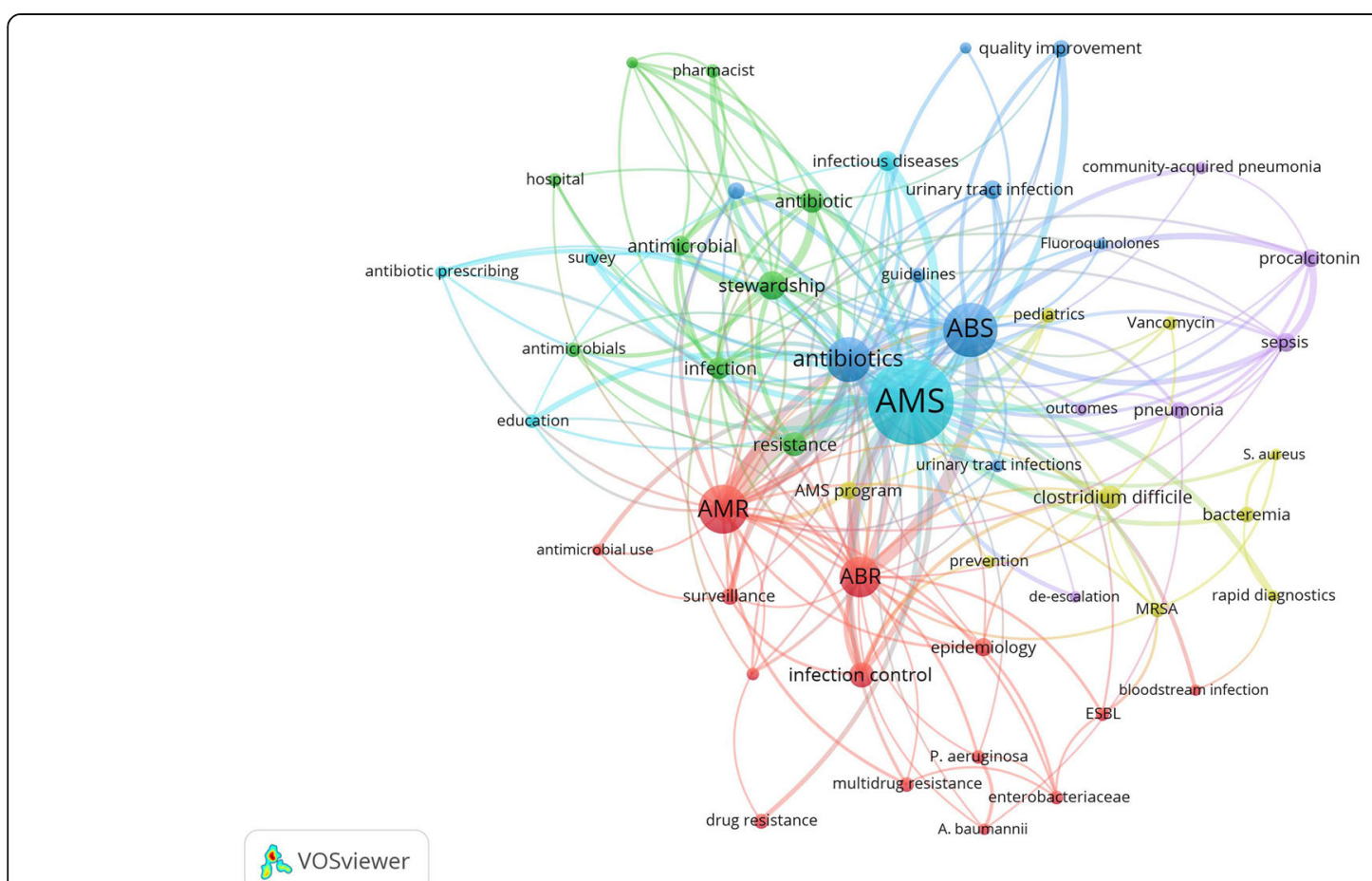

Fig. 2 Network visualization map of most frequent author keywords 
Table 1 Most frequent author keywords in AMS literature

\begin{tabular}{|c|c|c|c|c|c|c|c|}
\hline Keyword & $\begin{array}{l}\text { Number of } \\
\text { occurrences }\end{array}$ & Keyword & $\begin{array}{l}\text { Number of } \\
\text { occurrences }\end{array}$ & Keyword & $\begin{array}{l}\text { Number of } \\
\text { occurrences }\end{array}$ & Keyword & $\begin{array}{l}\text { Number of } \\
\text { occurrences }\end{array}$ \\
\hline $\begin{array}{l}\text { antimicrobial } \\
\text { stewardship }\end{array}$ & 819 & urinary tract infection & 69 & drug resistance & 44 & antibiotic prescribing & 35 \\
\hline $\begin{array}{l}\text { antibiotic } \\
\text { stewardship }\end{array}$ & 383 & sepsis & 67 & guidelines & 44 & urinary tract infections & 35 \\
\hline $\begin{array}{l}\text { antimicrobial } \\
\text { resistance }\end{array}$ & 318 & $\begin{array}{l}\text { antimicrobial } \\
\text { stewardship program }\end{array}$ & 63 & $\begin{array}{l}\text { multidrug } \\
\text { resistance }\end{array}$ & 44 & $\begin{array}{l}\text { community-acquired } \\
\text { pneumonia }\end{array}$ & 34 \\
\hline antibiotics & 276 & epidemiology & 61 & survey & 43 & outcomes & 34 \\
\hline $\begin{array}{l}\text { antibiotic } \\
\text { resistance }\end{array}$ & 239 & procalcitonin & 61 & education & 42 & rapid diagnostics & 32 \\
\hline stewardship & 129 & surveillance & 58 & vancomycin & 42 & $\begin{array}{l}\text { acinetobacter } \\
\text { baumannii }\end{array}$ & 31 \\
\hline infection control & 106 & quality improvement & 57 & esbl & 40 & antimicrobial use & 31 \\
\hline resistance & 101 & antibiotic use & 54 & hospital & 40 & de-escalation & 31 \\
\hline antibiotic & 98 & pneumonia & 54 & $\begin{array}{l}\text { Pseudomonas } \\
\text { aeruginosa }\end{array}$ & 39 & $\begin{array}{l}\text { emergency } \\
\text { department }\end{array}$ & 30 \\
\hline Clostridium difficile & 94 & bacteremia & 52 & enterobacteriaceae & 38 & bloodstream infection & 29 \\
\hline infection & 84 & mrsa & 47 & pharmacist & 38 & fluoroquinolones & 29 \\
\hline antimicrobial & 75 & antimicrobials & 46 & intensive care unit & 37 & long-term care & 29 \\
\hline $\begin{array}{l}\text { infectious } \\
\text { diseases }\end{array}$ & 74 & pediatrics & 46 & prevention & 36 & Staphylococcus aureus & 29 \\
\hline
\end{tabular}

AMS antimicrobial stewardship

Mapping of frequent terms in the abstracts of the retrieved documents gave three major clusters representing three major research themes. The three major research themes represented 686 articles with closely related abstract terms. The first research theme (red cluster, $n=255$ terms) discussed the knowledge, education, and practice of pharmacists about AMS. The second cluster (green cluster, $n=194$ terms) discussed the impact of AMS programs on length of hospital stay. The third research theme (blue cluster, $n=237$ terms) discussed the relationship between AMS programs and the development of resistance in various types of pathogens (Fig. 3).

Analysis of the retrieved documents based on geographical origin indicated that $172(3.9 \%)$ documents were from AFRO, 168 (3.8\%) from SEARO, 2111 (48.0\%) from AMRO, 1583 (36.0\%) from EURO, 157 (3.6\%) from the EMRO, and 584 (13.3\%) from WPRO. Publications from the AMRO region has the steepest increase in the number of publications. The EMRO, AFRO, and SEARO had similar growth pattern of publications which started after 2010 (Fig. 4). In 2019, the number of published documents for AMRO, EURO, WPRO, EMRO, SEARO, and AFRO was 427, 326, 155, 46, 43, and 50 documents respectively.

The list of top ten active countries included seven European countries, two in North America and one in the Western Pacific region. The USA led with 1834 (41.7\%) documents followed distantly by the UK with
$603(13.7 \%)$ documents. Table 2 shows the list of the top ten active countries.

Figure 5 presented the percentage of inter- versus intra-country research collaboration for each of the top ten active countries. The USA had the least percentage of documents with international authors (15.4\%) while Switzerland had the highest percentage of documents with international authors (67.2\%). The mean percentage of documents with international authors for the top ten active authors was $57 \%$.

The majority of the retrieved documents $(n=3693$, 83.9\%) were published by developed countries while the remaining were published by developing countries $(n=$ $759,17.2 \%)$. The research collaboration between the top ten active countries and developing countries with a minimum contribution of 10 documents was mapped. The map included 47 countries; ten developed countries which appeared in the active list and 37 developing countries. The map showed that the active countries (developed) were in the center of the map and within a close distance to each other. The connecting lines between the developed countries were thick suggestive of relatively strong research collaboration. The connecting lines between developing and developed countries were thin suggestive of relatively weak research collaboration (Fig. 6).

Table 3 shows the top ten active institutions. The US CDC $(n=93,2.1 \%)$ ranked first followed by the Imperial College London $(n=86,2.0 \%)$ and the Health Protection 


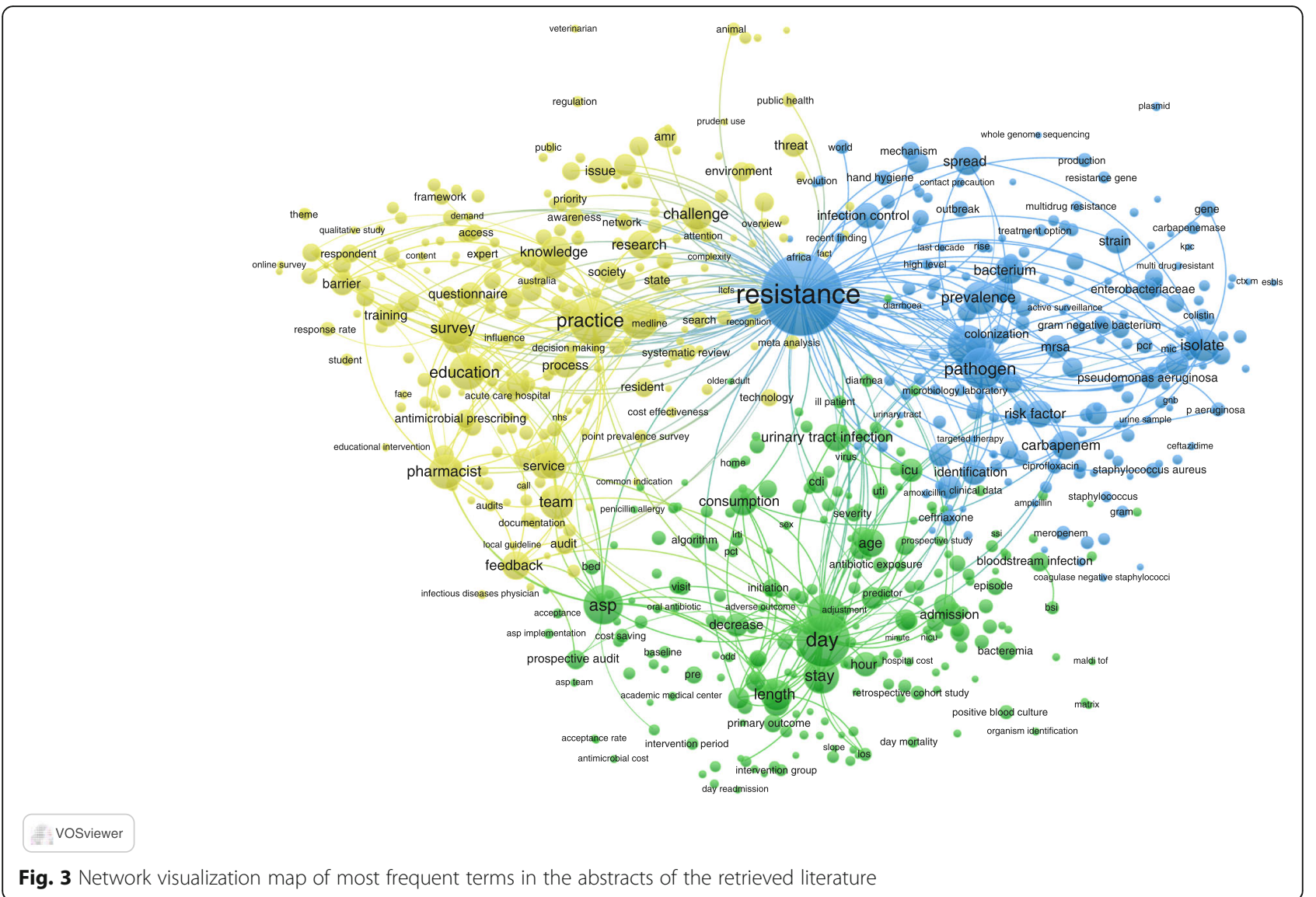

Fig. 3 Network visualization map of most frequent terms in the abstracts of the retrieved literature

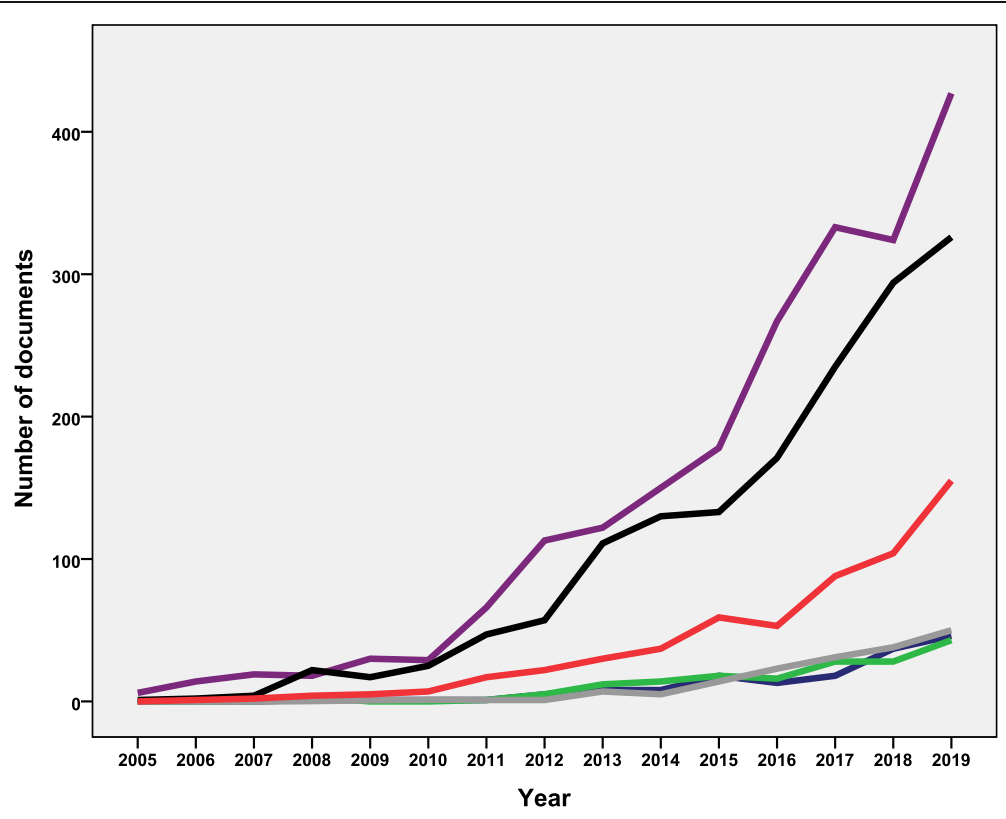

Fig. 4 Annual growth of publications on AMS in each WHO region (Purple line: the region of the Americas. Black line: the European region. Red line: the Western Pacific region. The remaining overlapping lines represent the Eastern Mediterranean region, African region, and the South-East Asian region 
Table 2 Top ten active countries on AMS research

\begin{tabular}{llll}
\hline Rank & Country & Frequency & $\mathbf{N}$ \\
\hline 1st & United States & 1834 & 41.7 \\
2nd & United Kingdom & 603 & 13.7 \\
3rd & Australia & 284 & 6.5 \\
4th & Germany & 268 & 6.1 \\
5th & Canada & 253 & 5.7 \\
6th & France & 213 & 4.8 \\
7th & Italy & 199 & 4.5 \\
8th & Netherlands & 165 & 3.7 \\
9th & Spain & 140 & 3.2 \\
10th & Switzerland & 122 & 2.8 \\
\hline
\end{tabular}

AMS antimicrobial stewardship

Agency (86; 1.8\%). The list of active institutions included six academic and four non-academic institutions.

Table 4 shows the top ten active journals. The Infection Control and Hospital Epidemiology journal $(n=245$, 5.6\%) ranked first followed by the Journal of Antimicrobial Chemotherapy $(n=176,4.0 \%)$. The majority of active journals were based in the US or the United Kingdom (UK) and all active journals ranked Q1 in the field of infectious diseases. Documents published in the Clinical Infectious
Diseases received the highest number of citations per document (70.7).

The total number of authors publishing on AMS was 15,225 , of which $125(0.8 \%)$ published more than ten documents and 14,462 (96.3\%) authors published less than five documents. The co-authorship network map of authors with a minimum of 10 publications is shown in Fig. 7. Authors with the largest node size contributed the most and included Pulcini, C.; Srinivasan, A.; Goff, D.A.; Newland, J.G.; Hersh, A.L.; Nathwani, D.; Gerber, J.S.; Gould, I.M.; Daneman, N.; and Cosgrove, S.E.

Analysis of funding showed that 1928 (43.8\%) documents on AMS were funded. The National Institute of Health ( $n=158,3.6 \%$ ) was the most active funding sponsor followed by the international pharmaceutical Companies; Pfizer $(n=68 ; 1.5 \%)$ and Merck $(n=56,1.3 \%)$. Other pharmaceutical companies such as Bayer $(n=20$, $0.5 \%)$ and AstraZeneca $(n=19,0.4 \%)$ were among the top active funding sponsors.

\section{Discussion}

In the current study, peer-reviewed literature on AMS was investigated and descriptive indicators were presented. The current study showed a 14-fold increase in the number of publications in the last decade. This increase came as a result of (1) the seriousness and the

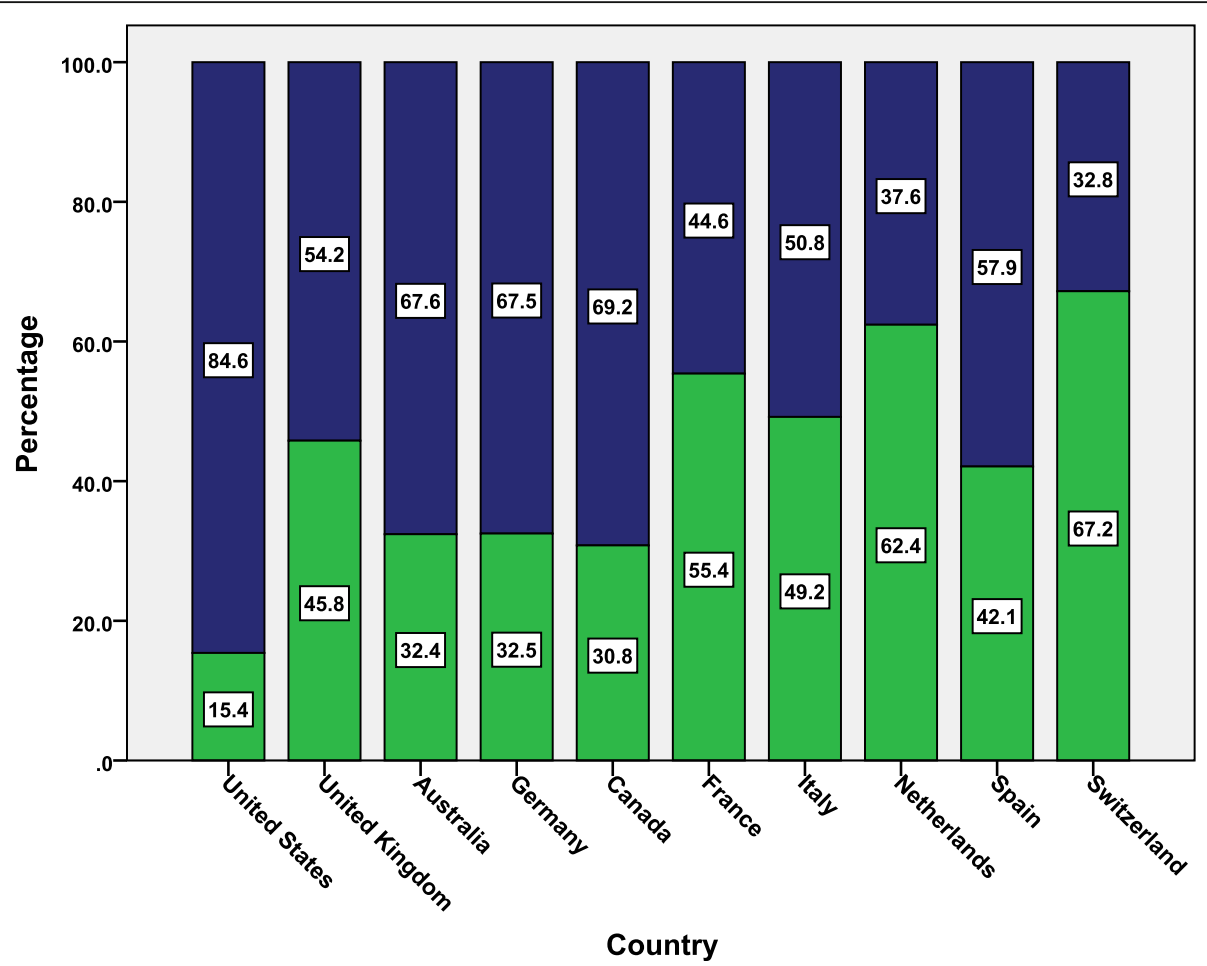

Fig. 5 International research collaboration for top ten active countries. Green bars represent multiple country publications (international/intercountry collaboration) while the blue chart represent single country publication (intra-country publication) 


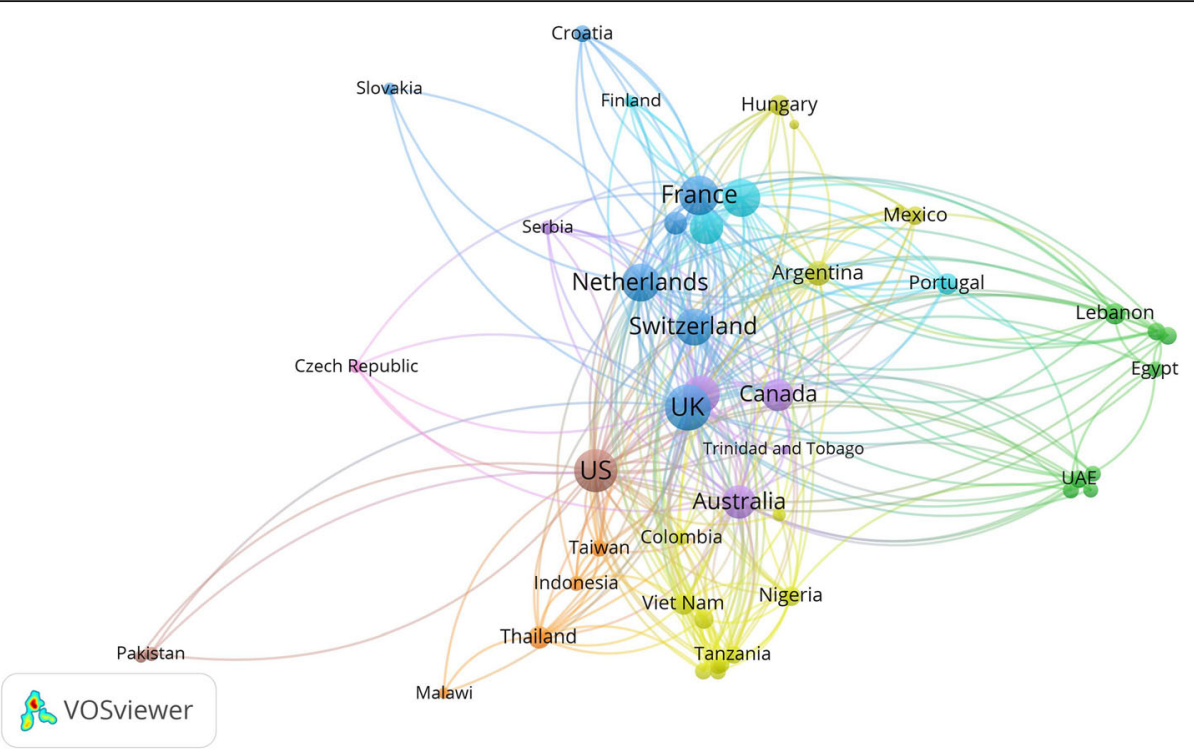

Fig. 6 Network visualization map of research collaboration between top ten active countries (developed countries) and 37 developing countries. Each of the developing countries has a contribution of 10 documents at least

global dimension of AMR [43], (2) the important role of the 574 implemented AMS programs in improving certain patient health outcomes and cost reduction [39, 44], (3) the increasing calls and recommendations made by health organizations such as the SHEA and Infectious Diseases Society of America (IDSA) to combat AMR [45-47], and (4) the awareness of WHO member states to implement policies to achieve objective number 4 of the GAP to combat AMR [9].

The current study indicated that authors from the US have the highest contribution to the retrieved documents. In 2014, the US CDC called on all hospitals in the USA to implement antibiotic stewardship programs and released the guidelines for implementing such stewardship (Core Elements of Hospital Antibiotic
Stewardship Programs) [48]. In 2015, "The United States National Action Plan for Combating Antibiotic Resistant Bacteria" set a goal for implementation of the Core Elements in all hospitals that receive federal funding [49]. This means that the control of AMR requires active involvement of the policy changes. The WHO released a toolkit in 2019 to implement AMS in low- and middleincome countries [9] to facilitate and help low- and middle-income countries in combating AMR. It should be emphasized that the steep growth in the number of publications does not necessarily imply the effectiveness of AMS in reducing antimicrobial resistance. A recent systematic review on the quality of studies evaluating antimicrobial stewardship interventions concluded that the overall quality of antimicrobial stewardship studies is

Table 3 Top ten active institutions/organizations on AMS research

\begin{tabular}{|c|c|c|c|c|}
\hline Rank $^{a}$ & Institution/Organization & Frequency & $\begin{array}{l}\% \\
N=4402\end{array}$ & Country \\
\hline $1 s t$ & Centers for Disease Control and Prevention & 93 & 2.1 & USA \\
\hline 2nd & Imperial College London & 86 & 2.0 & UK \\
\hline $3 \mathrm{rd}$ & Health Protection Agency & 80 & 1.8 & UK \\
\hline 4th & University of Toronto & 79 & 1.8 & Canada \\
\hline 5 th & University of Pennsylvania & 74 & 1.3 & USA \\
\hline 6th & Public Health England & 71 & 1.6 & UK \\
\hline 7th & University of Melbourne & 70 & 1.6 & Australia \\
\hline 8th & The Children's Hospital of Philadelphia & 63 & 1.4 & USA \\
\hline 9th & Monash University & 56 & 1.3 & Australia \\
\hline 9th & The University of Utah & 56 & 1.3 & USA \\
\hline
\end{tabular}

AMS antimicrobial stewardship

an ranking, two equally active institutions/organizations were given similar ranks and one position in the rank was skipped 
Table 4 Top ten active journals on AMS research

\begin{tabular}{|c|c|c|c|c|c|c|}
\hline Rank $^{a}$ & Journal & Frequency & $\begin{array}{l}\% \\
N=4402\end{array}$ & $\begin{array}{l}\text { Citations per } \\
\text { document }\end{array}$ & Country & Journal Rank \\
\hline 1 st & Infection Control And Hospital Epidemiology & 245 & 5.6 & 16.2 & UK & Q1 \\
\hline 2nd & Journal Of Antimicrobial Chemotherapy & 176 & 4.0 & 24.5 & USA & Q1 \\
\hline $3 \mathrm{rd}$ & Clinical Infectious Diseases & 134 & 3.0 & 70.7 & UK & Q1 \\
\hline 4th & American Journal Of Infection Control & 123 & 2.8 & 12.6 & USA & Q1 \\
\hline 5th & Plos One & 75 & 1.7 & 15.5 & USA & Q1 \\
\hline 6th & International Journal Of Antimicrobial Agents & 68 & 1.5 & 17.7 & Netherlands & Q1 \\
\hline 7th & American Journal Of Health System Pharmacy & 67 & 1.5 & 13.7 & USA & Q1 \\
\hline 7th & Antimicrobial Resistance And Infection Control & 67 & 1.5 & 10.4 & UK & Q1 \\
\hline 9th & Journal Of Hospital Infection & 63 & 1.4 & 12.5 & UK & Q1 \\
\hline 10th & Clinical Microbiology And Infection & 61 & 1.4 & 26.2 & UK & Q1 \\
\hline 10th & Open Forum Infectious Diseases & 61 & 1.4 & 5.5 & USA & Q1 \\
\hline
\end{tabular}

AMS antimicrobial stewardship

${ }^{a}$ In ranking, two equally active journals were given similar ranks and one position in the rank was skipped

Q1 = first quartile = highest rank. The information regarding journal ranking was obtained from Scimajo Journal Rank

low with no clinical and microbiological outcome data [37]. Another recent systematic review on the effectiveness of AMS concluded that there is no solid evidence that AMS programs are effective in reducing antibiotic resistance in hospital settings and further stronger studies are needed to reach solid conclusions [34].
The current study indicated that $C$. difficile was frequently encountered author keyword in the retrieved literature on AMS [50-58]. In the 2019 Antibiotic Resistance Threats Report, the U.S. CDC has declared C. difficile infections as an urgent threat $[59,60]$. In the European point prevalence study, $C$. difficile ranked sixth among microorganisms responsible for healthcare-associated infections

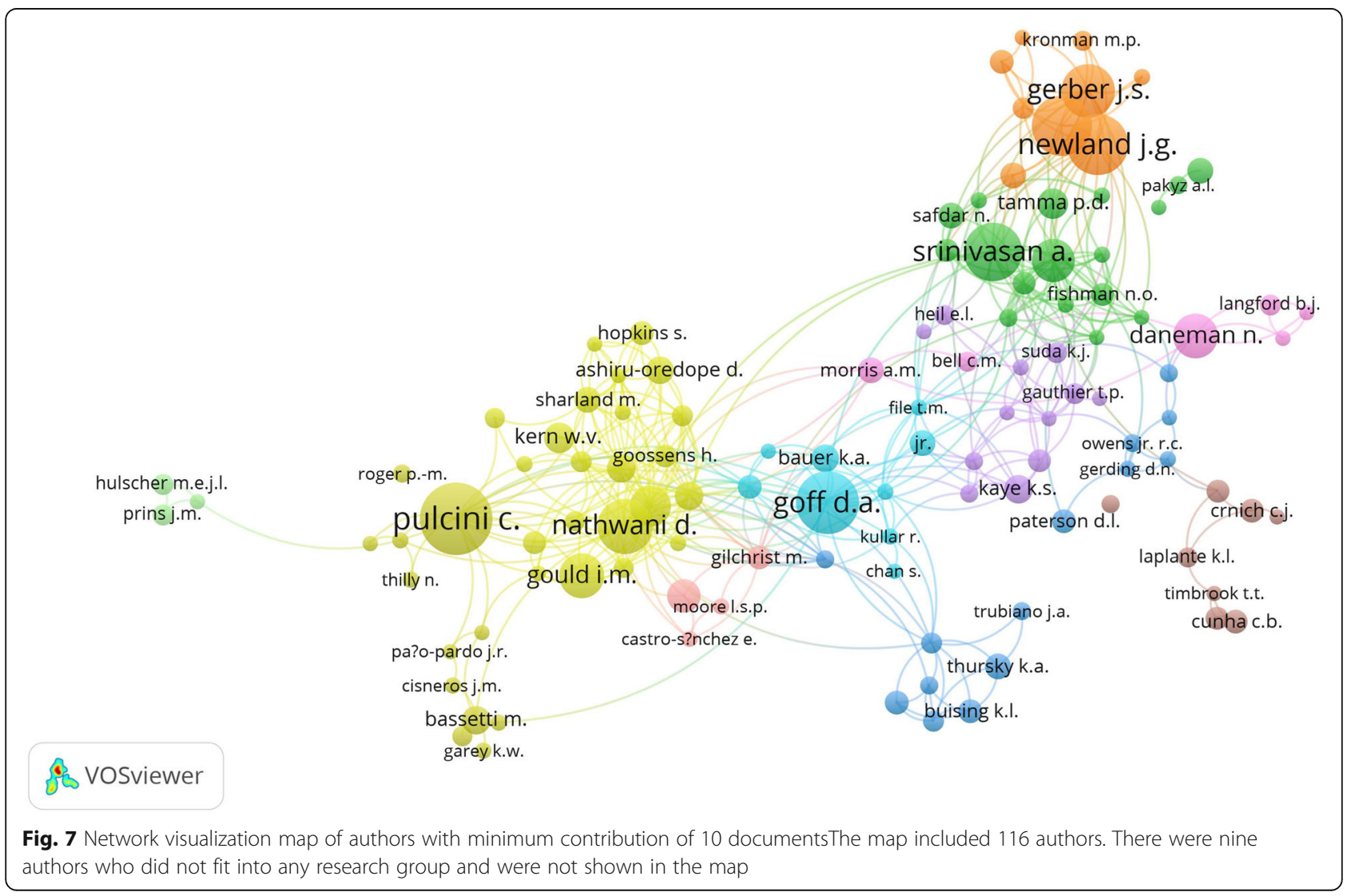


[61]. It is believed that the majority of $C$. difficile in the United States are hospital-acquired [62]. A recent systematic review of 229 publications from 41 countries that the overall rate of CDI in healthcare facilities was 2.24 (95\% confidence interval $\mathrm{CI}=1.66-3.03$ ) per 1000 admissions/ year [63]. The impact of AMS programs on CDI is controversial. Certain studies indicated that AMS caused a significant reduction in $C$. difficile infections $[52,53]$ while other studies did not $[50,57,58]$.

In the current study, rapid diagnosis of causative microbes was among the most frequent author keywords found in AMS literature. Effective antimicrobial stewardship is closely linked with the availability of techniques that can make correct and rapid diagnoses. For example, many types of viral respiratory infections are clinically indistinguishable from bacterial respiratory infections which leads to overuse or misuse of broad-spectrum antibiotics [64, 65]. Rapid diagnostic methods are important for implementing effective AMS programs given that traditional microbiological testing methods requires 2-4 days resulting in empirical treatment with strong and broad- spectrum antibiotics before the results of microbiological diagnostics are known [66]. Therefore, rapid diagnostics is a key goal of AMS to reduce unnecessary antibiotic use [67]. Integration of rapid diagnostic testing in AMS programs has the potential for early organism identification with significant improvement in patient outcomes and cost [68-73]. Rapid diagnostic tools and microbial identification along with the appropriate antibiotic administration is critical in patients with serious infections such as sepsis [74-78]. Therefore, rapid diagnostic and identification tools provide an excellent opportunity for all healthcare specialists to collaborate and reach a rational and timely decision in critical situations. The implementation of new technology for rapid diagnosis in AMS programs might increase the cost and reduce savings $[79,80]$. Studies indicated that evidence for the advantages of rapid tests in bloodstream infections seems strong while that for respiratory and gastrointestinal infections are still poor [74, 81-83].

The current study showed that the bulk of the publications on AMS came from the AMRO and EURO. The leading role of these two regions in AMS was also visible in other health-related fields $[84,85]$. The presence of the US CDC and European CDC and various specialized academic and governmental institutions in public health and infectious diseases gave the region of the Americas and the European region a leading role.

The current study showed that the contribution of China to the literature on AMS was not visible in the top active list. China participated in publishing 99 documents (data not shown) while Switzerland which ranked 10th in the list participated in publishing 122 documents. Most of the published document from China originated from academic institutions and the Chinese CDC did not play a key role in these publications. It is possible that most publications on stewardship from China were published in national Chinese journals or as grey literature, i.e. reports, governmental brochures, articles in newspapers and others. In the current study, such grey literature was not included. The same argument applies to other world regions and countries which showed a limited contribution to this subject. Antimicrobial consumption increased by $79 \%$ in China between 2000 and 2015, which was higher than the increase in global antimicrobial consumption [86]. The Chinese government took multiple measures to strengthen the AMS to improve the intelligent use of antibiotics and therefore to combat the increasing rates of AMR in China [87, 88]. In 2016, China also launched its National Action Plan to Contain Antimicrobial Resistance (2016-2020) mainly to optimize antimicrobial consumption and antimicrobial resistance [89]. It should be emphasized that active journals in publishing documents on AMS were based in the USA and Europe. This might have created a certain bias toward countries in which these prestigious journals and publishers are based.

International research collaboration is known to increase research productivity and impact [90-92]. It is expected that the global situation of AMR is worsened by limited international research collaboration. Most policymakers in different world regions are keen to implement the WHO recommendation of implementing AMS. However, the limited number of experts and specialized institutions might hinder researchers in many countries to investigate AMS. International research collaboration is important for countries in AFRO, EMRO, Latin America, and SEARO where experts can help in assessing the situation and help implement AMS along with other strategies. The current study showed limited research collaboration in the field of AMS between developed and developing countries. Several studies discussed international research collaboration in different fields $[93,94]$. A relatively recent study on AMR in the Asia-Pacific region recommended inter-country collaboration to contain the escalating rates of AMR [95]. A second recently published article with the title "Challenges and opportunities for antimicrobial stewardship in resource-rich and resource-limited countries" discussed in details the challenges in implementing AMS programs in rich and poor countries [96]. Collaboration in the field of AMS and AMR research between developed and developing countries is extremely important for global health security given the limited knowledge and experience in most developing countries about AMR [97-103].

The current study also showed that publications on AMS had a high scientific impact as assessed by the $h$-index relative to other publications in the field of microbiology, 
infections, and antimicrobials [23, 25, 26, 104-106]. This indicates that the subject is of interest to a diverse number of readers and researchers. The association between AMS and AMR is one potential reason for attracting many citations. The annual campaigns by the $\mathrm{WHO}$ to increase awareness of the public about antibiotic resistance was also a key element in drawing attention to this subject [107]. Many several other agencies played an influential role in promoting AMS research and implementation such as Alliance for the Prudent Use of Antimicrobials, British Society for Antimicrobial Chemotherapy, US CDC, European Centre for Disease Prevention and Control, HealthCare Infection Control Special Interest Group, IDSA, SHEA, and The Dutch Working Party on Antibiotic Policy. Several campaigns were carried out by these agencies to improve antimicrobial use such as "Get Smart" from the US CDC and European Antibiotic Awareness Day. Endorsement of the G20 to take action against AMR gave momentum to research activity and citations in this field [108]. Publishing more than a quarter of the retrieved documents in leading journals in the field of infectious diseases and antimicrobial therapy also played a positive role in attracting a larger number of citations [109-111]. Finally, the heavy involvement of governmental and non-governmental bodies, as well as multinational huge pharmaceutical companies in funding research on AMS, attracted the attention of clinicians, scientists, and healthcare providers to the significance of this subject. All these factors are known to increase research activity and citations to a certain subject [109-112].

\section{Limitation}

The current study has a few limitations. The literature on AMS has been retrieved from journals indexed in Scopus while grey literature and publications in nonindexed journals have not been studied. This means that a certain number of publications particularly from EMRO, SEARO, and AFRO where most national journals are not indexed in Scopus has been missed. If this is the case, then the current study has underestimated the productivity from these regions. Another limitation is the method of counting publications for countries, authors, and institutions. Scopus counts a document once for each author. The same applies for counting documents for countries and institutions when there were different affiliations on the same document. This means that there was an overlap in the results and that the results of certain countries, institutions, and active authors might be over-estimated. Finally, the search query was developed to retrieve all potential documents in the field of AMS. However, the presence of false-positive or falsenegative results remains a possibility.

\section{Conclusions}

The current study is the first bibliometric study on AMS. The study came as a response to global calls to strengthen the fight and increase awareness about AMR. The current study showed skewed results toward highincome countries. The focus of the current literature on AMS was directed toward several themes such as reduction of antimicrobial use, cost-effectiveness, pharmacist knowledge and practice, length of hospital stay, rapid diagnostics of microbes in critical settings, and impact on microbial resistance. Research and implementation of AMS need to be globalized and given a priority in the fight against AMR. National action plans in low and middle-income countries need to provide funding for implementation, research, and awareness campaigns about AMR to fulfill the commitment of containment of AMR. Researchers and clinicians in low- and middleincome countries need to establish connections and collaborations with peers in high-income countries to implement and carry out research on AMS. The global effort needs to be coordinated to fight AMR and fulfill the international goals of SDGs.

\begin{abstract}
Abbreviations
AMS: Antimicrobial stewardship; AMR: Antimicrobial resistance; GAP: Global Action Plan; WHO: World Health Organization; CDC: Centers for Disease Control and Prevention; USA: United States of America; UK: United Kingdom; Q1: First Quartile; SDG: Sustainable Development Goal; ECDC: European

Centers of Disease Control and Prevention
\end{abstract}

\section{Acknowledgements}

The author would like to thank An-Najah National University for giving me the opportunity to access most recent information sources.

\section{Author's contributions}

W.S started the idea, designed the methodology; did the data analysis, graphics, and data interpretation; wrote and submitted the manuscript. This was a single-authored manuscript. The author(s) read and approved the final manuscript.

\section{Funding}

None.

Availability of data and materials

All data presented in this manuscript are available on Scopus database using the search query listed in the methodology section.

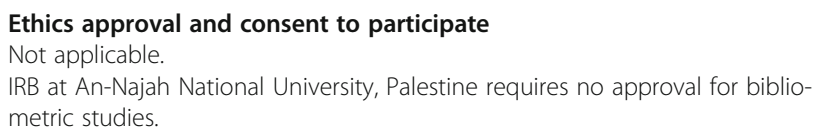

Consent for publication

Not applicable.

\section{Competing interests}

The authors declare that they have no competing interests.

Received: 5 October 2020 Accepted: 14 December 2020

Published online: 04 January 2021

\section{References}

1. Christaki E, Marcou M, Tofarides A. Antimicrobial resistance in Bacteria: mechanisms, evolution, and persistence. J Mol Evol. 2019. 
2. Karakonstantis S, Kalemaki D. Antimicrobial overuse and misuse in the community in Greece and link to antimicrobial resistance using methicillinresistant S. aureus as an example. J Infect Public Health. 2019;12(4):460-4.

3. Tangcharoensathien V, Chanvatik S, Sommanustweechai A. Complex determinants of inappropriate use of antibiotics. Bull World Health Organ. 2018;96(2):141-4.

4. Mclntosh W, Dean W. Factors associated with the inappropriate use of antimicrobials. Zoonoses Public Health. 2015;62(s1):22-8.

5. Rhee C, Aol G, Ouma A, Audi A, Muema S, Auko J, Omore R, Odongo G, Wiegand RE, Montgomery JM, et al. Inappropriate use of antibiotics for childhood diarrhea case management - Kenya, 2009-2016. BMC Public Health. 2019:19.

6. Agnihotry A, Al-Langawi JH, Khanna A. Inappropriate use of antibiotics in dentistry. Journal of the Bahrain Medical Society. 2014;25(1):55-6.

7. Joyce J, Langsjoen J, Sharadin C, Kuehl TJ, Larsen WI. Inappropriate use of antibiotics in patients undergoing gynecologic surgery. Proc (Bayl Univ Med Cent). 2017;30(1):30-2

8. van Heijl I, Schweitzer VA, Zhang L, van der Linden PD, van Werkhoven $\mathrm{CH}$, Postma DF. Inappropriate use of antimicrobials for lower respiratory tract infections in elderly patients: patient- and community-related implications and possible interventions. Drugs Aging. 2018;35(5):389-98.

9. World Health Organization (WHO):Global action plan on antimicrobial resistance [https://www.who.int/antimicrobial-resistance/global-action-plan/en/].

10. United Nations (UN): Political Declaration in the UN general Assembly High Level Meeting In.; 2017.

11. World Health Organization (WHO):Ten threats to global health in 2019 [https://www.who.int/emergencies/ten-threats-to-global-health-in-2019].

12. Gerding DN. The search for good antimicrobial stewardship. The Joint Commission journal on quality improvement. 2001;27(8):403-4.

13. Dyar OJ, Huttner B, Schouten J, Pulcini C. What is antimicrobial stewardship? Clinical microbiology and infection. 2017;23(11):793-8.

14. Silverberg SL, Zannella VE, Countryman D, Ayala AP, Lenton E, Friesen F, Law M. A review of antimicrobial stewardship training in medical education. Int J Med Educ. 2017:8:353-74.

15. Aguilera-Alonso D, Escosa-García L, Saavedra-Lozano J, Cercenado E, Baquero-Artigao F. Carbapenem-Resistant Gram-Negative Bacterial Infections in Children. Antimicrob Agents Chemother. 2020:64(3).

16. Folgori L, Bielicki J. Future challenges in pediatric and neonatal Sepsis: emerging pathogens and antimicrobial resistance. J Pediatr Intensive Care. 2019;8(1):17-24

17. Rodrigo-Troyano A, Sibila $\mathrm{O}$. The respiratory threat posed by multidrug resistant Gram-negative bacteria. Respirology (Carlton, Vic). 2017;22(7): 1288-99

18. Kallen AJ, Srinivasan A. Current epidemiology of multidrug-resistant gramnegative bacilli in the United States. Infect Control Hosp Epidemiol. 2010; 31(Suppl 1):S51-4.

19. Centers for Disease Control and Prevention (CDC):Antibiotic/Antimicrobial Resistance [https://www.cdc.gov/drugresistance/about.html].

20. World Health Organization (WHO): Antimicrobial Stewardship Programmes in healthcare facilities in Low- and Middle-income countries: a WHO practical toolkit. In. Geneva; 2019.

21. Sweileh WM. Bibliometric analysis of peer-reviewed literature in transgender health (1900 - 2017). BMC Int Health Hum Rights. 2018;18(1):16.

22. Sweileh WM, Al-Jabi SW, Zyoud SH, Sawalha AF. Bibliometric analysis of literature in pharmacy education: 2000-2016. Int J Pharmacy Pract. 2018; 26(6):541-9.

23. Sweileh WM. Global research trends of World Health Organization's top eight emerging pathogens. Glob Health. 2017;13(1):9.

24. Sweileh WM, Al-Jabi SW, Sawalha AF, AbuTaha AS, Zyoud SH. Bibliometric Analysis of Worldwide Publications on Antimalarial Drug Resistance (20062015). Malar Res Treat. 2017(2017):6429410.

25. Sweileh WM, Al-Jabi SW, Zyoud SH, Sawalha AF, Abu-Taha AS. Global research output in antimicrobial resistance among uropathogens: a bibliometric analysis (2002-2016). J Glob Antimicrob Resist. 2018;13: 104-14.

26. Sweileh WM, Sawalha AF, Al-Jabi S, Zyoud SH. Bibliometric analysis of literature on antifungal triazole resistance: 1980-2015. Germs. 2017;7(1): 19-27.

27. Sweileh WM, Sawalha AF, Al-Jabi SW, Zyoud SH, Shraim NY, Abu-Taha AS. A bibliometric analysis of literature on malaria vector resistance: (1996 - 2015). Glob Health. 2016;12(1):76.
28. El-Berry DK. Scientific-publication contributions of Egyptian faculties of veterinary medicine indexed in PubMed between 2000 and 2014: a comparative Bibliometric analysis. Qualitative and Quantitative Methods in Libraries. 2017:4(2):433-49.

29. Falagas ME, Pitsouni El, Malietzis GA, Pappas G. Comparison of PubMed, Scopus, web of science, and Google scholar: strengths and weaknesses. FASEB J. 2008;22(2):338-42.

30. Sweileh WM, Wickramage K, Pottie K, Hui C, Roberts B, Sawalha AF, Zyoud $\mathrm{SH}$. Bibliometric analysis of global migration health research in peerreviewed literature (2000-2016). BMC Public Health. 2018;18(1):777.

31. Sweileh WM. Global research output on HIV/AIDS-related medication adherence from 1980 to 2017. BMC Health Serv Res. 2018;18(1):765.

32. Lindsay PJ, Rohailla S, Taggart LR, Lightfoot D, Havey T, Daneman N, Lowe C, Muller MP. Antimicrobial stewardship and intensive care unit mortality: a systematic review. Clin Infect Dis. 2019;68(5):748-56.

33. Wu JH, Langford BJ, Daneman N, Friedrich JO, Garber G. Antimicrobial stewardship programs in long-term care settings: a meta-analysis and systematic review. J Am Geriatr Soc. 2019;67(2):392-9.

34. Bertollo LG, Lutkemeyer DS, Levin AS. Are antimicrobial stewardship programs effective strategies for preventing antibiotic resistance? A systematic review. Am J Infect Control. 2018;46(7):824-36.

35. Rittmann B, Stevens MP. Clinical decision support systems and their role in antibiotic stewardship: a systematic review. Curr Infect Dis Rep. 2019;21(8):29.

36. Nguyen $\mathrm{HQ}$, Tunney MM, Hughes $\mathrm{CM}$. Interventions to improve antimicrobial stewardship for older people in care homes: a systematic review. Drugs Aging. 2019;36(4):355-69.

37. Schweitzer VA, van Heijl I, van Werkhoven CH, Islam J, Hendriks-Spoor KD Bielicki J, Bonten MJM, Walker AS, Llewelyn MJ. Consensus on antimicrobial stewardship evaluations study g: the quality of studies evaluating antimicrobial stewardship interventions: a systematic review. Clinica Microbiology Infect. 2019;25(5):555-61.

38. Araujo da Silva AR, Albernaz de Almeida Dias DC, Marques AF, Biscaia di Biase C, Murni IK, Dramowski A, Sharland M, Huebner J, Zingg W. Role of antimicrobial stewardship programmes in children: a systematic review. J Hosp Infect. 2018;99(2):117-23.

39. Nathwani D, Varghese D, Stephens J, Ansari W, Martin S, Charbonneau C. Value of hospital antimicrobial stewardship programs [ASPs]: a systematic review. Antimicrob Resist Infect Control. 2019;8(1):35.

40. Nam CW. World Economic Outlook for 2020 and 2021. In: CESifo Forum: 2020: Institut für Wirtschaftsforschung (Ifo); 2020. p. 58-9.

41. van Eck NJ, Waltman L. Software survey: VOSviewer, a computer program for bibliometric mapping. Scientometrics. 2010;84(2):523-38.

42. JE MG Jr, Gerding DN. Does antibiotic restriction prevent resistance? New Horizons: Science and Practice of Acute Medicine. 1996;4(3):370-6.

43. O'neill J. Antimicrobial resistance: tackling a crisis for the health and wealth of nations. Rev Antimicrob Resist. 2014;20:1-16.

44. Ibrahim NH, Maruan K, Mohd Khairy HA, Hong YH, Dali AF, Neoh CF. Economic evaluations on antimicrobial stewardship Programme: a systematic review. J Pharmacy \& Pharmaceutical Sciences. 2017;20(1): 397-406

45. Barlam TF, Cosgrove SE, Abbo LM, Macdougall C, Schuetz AN, Septimus EJ, Srinivasan A, Dellit TH, Falck-Ytter YT, Fishman NO, et al. Implementing an antibiotic stewardship program: guidelines by the Infectious Diseases Society of America and the Society for Healthcare Epidemiology of America. Clin Infect Dis. 2016;62(10):e51-77.

46. Dellit TH, Owens RC, McGowan JE Jr, Gerding DN, Weinstein RA, Burke JP, Huskins WC, Paterson DL, Fishman NO, Carpenter CF, et al. Infectious Diseases Society of America and the Society for Healthcare Epidemiology of America guidelines for developing an institutional program to enhance antimicrobial stewardship. Clin Infect Dis. 2007; 44(2):159-77.

47. Shlaes DM, Gerding DN, John JF Jr, Craig WA, Bornstein DL, Duncan RA, Eckman MR, Farrer WE, Greene WH, Lorian V, et al. Society for healthcare epidemiology of america and infectious diseases society of america joint committee on the prevention of antimicrobial resistance: guidelines for the prevention of antimicrobial resistance in hospitals. Clin Infect Dis. 1997;25(3): 584-99

48. United States Centers for Disease Prevention and Control (US CDC): The Core Elements of Hospital Antibiotic Stewardship Programs: 2019. In.; 2019.

49. House TW: National Action Plan For Comabating Antibiotic - Resistant Bacteria In.; 2015. 
50. Yoshida J, Kikuchi T, Ueno T, Mataga A, Asano I, Otani K, Tamura T, Tanaka M. Interprofessional antimicrobial stewardship influencing Clostridioides difficile infection: an 8-year study using antimicrobial use density. Infect Drug Resist. 2019;12:3409-14.

51. Rosa R, Donskey CJ, Munoz-Price LS. The intersection between colonization resistance, antimicrobial stewardship, and Clostridium difficile. Curr Infect Dis Rep. 2018;20(8):27.

52. Patton A, Davey P, Harbarth S, Nathwani D, Sneddon J, Marwick CA. Impact of antimicrobial stewardship interventions on Clostridium difficile infection and clinical outcomes: segmented regression analyses. J Antimicrob Chemother. 2018;73(2):517-26.

53. Moffa MA, Walsh TL, Tang A, Bremmer DN. Impact of an antimicrobial stewardship program on healthcare-associated Clostridium difficile rates at a community-based teaching hospital. J Infect Prev. 2018;19(4):191-4.

54. Mijovic B, Dubravac Tanaskovic M, Racic M, Bojanic J, Stanic S, Bankovic Lazarevic D. Outcomes of intrahospital antimicrobial stewardship programs related to prevention of Clostridium difficile infection outbreaks. Med Glas (Zenica). 2018;15(2):122-31.

55. Kamiyama D, Weng BH, Donnelley MA, Zhu E, Brown J. Use of a Clostridium difficile clinical prediction rule to facilitate antimicrobial stewardship. J Infect Prev. 2019:20(5):250-3.

56. Scott RD 2nd, Slayton RB, Lessa FC, Baggs J, Culler SD, McDonald LC, Jernigan JA. Assessing the social cost and benefits of a national requirement establishing antibiotic stewardship programs to prevent Clostridioides difficile infection in US hospitals. Antimicrob Resist Infect Control. 2019;8(1):17.

57. Christensen AB, Barr VO, Martin DW, Anderson MM, Gibson AK, Hoff BM, Sutton SH, Widmaier V, Salim AA, Silkaitis C, et al. Diagnostic stewardship of C. difficile testing: a quasi-experimental antimicrobial stewardship study. Infect Control Hosp Epidemiol. 2019:40(3):269-75.

58. Chia BY, Teo JQ, Lee W, Liew YX, Ee RP, Chlebicki MP, Oon LL, Kwa AL. Do antimicrobial stewardship programme interventions reduce the rate of and protect against Clostridium difficile infection? J Global Antimicrobial Resistance. 2019;17:312-5.

59. centers for Disease Control and Prevention (CDC):Antibiotic / Antimicrobial Resistance (AR / AMR) - Biggest Threats and Data [https://www.cdc.gov/ DrugResistance/biggest-threats.html].

60. Centers for Disease Control and Prevention (CDC): Antibiotic Resistance Threats in the United States, 2019. In.; 2019.

61. Suetens $C$, Latour K, Kärki T, Ricchizzi E, Kinross P, Moro ML, Jans B, Hopkins S, Hansen S, Lyytikäinen O. Prevalence of healthcare-associated infections, estimated incidence and composite antimicrobial resistance index in acute care hospitals and long-term care facilities: results from two European point prevalence surveys, 2016 to 2017. Eurosurveillance. 2018;23(46):1800516.

62. Lessa FC, Mu Y, Bamberg WM, Beldavs ZG, Dumyati GK, Dunn JR, Farley MM, Holzbauer SM, Meek JI, Phipps EC, et al. Burden of Clostridium difficile infection in the United States. N Engl J Med. 2015;372(9):825-34.

63. Balsells E, Shi T, Leese C, Lyell I, Burrows J, Wiuff C, Campbell H, Kyaw MH, Nair H. Global burden of Clostridium difficile infections: a systematic review and meta-analysis. Journal of global health. 2019;9:1.

64. Zumla A, Al-Tawfiq JA, Enne VI, Kidd M, Drosten C, Breuer J, Muller MA, Hui $D$, Maeurer M, Bates M. Rapid point of care diagnostic tests for viral and bacterial respiratory tract infections-needs, advances, and future prospects. Lancet Infect Dis. 2014;14(11):1123-35.

65. Chose YP. Making the correct diagnosis: the cornerstone of antibiotic stewardship; 2017

66. Bauer KA, Perez KK, Forrest GN, Goff DA. Review of rapid diagnostic tests used by antimicrobial stewardship programs. Clinical infectious diseases. 2014;59(suppl_3):S134-45.

67. Goff DA, Kullar R, Bauer KA, File TM Jr. Eight habits of highly effective antimicrobial stewardship programs to meet the joint commission standards for hospitals. Clin Infect Dis. 2017;64(8):1134-9.

68. Huang AM, Newton D, Kunapuli A, Gandhi TN, Washer LL, Isip J, Collins CD, Nagel JL. Impact of rapid organism identification via matrix-assisted laser desorption/ionization time-of-flight combined with antimicrobial stewardship team intervention in adult patients with bacteremia and candidemia. Clin Infect Dis. 2013;57(9):1237-45.

69. Perez KK, Olsen RJ, Musick WL, Cernoch PL, Davis JR, Peterson LE, Musse JM. Integrating rapid diagnostics and antimicrobial stewardship improves outcomes in patients with antibiotic-resistant gram-negative bacteremia. J Inf Secur. 2014;69(3):216-25.
70. Wenzler E, Goff DA, Mangino JE, Reed EE, Wehr A, Bauer KA. Impact of rapid identification of Acinetobacter Baumannii via matrix-assisted laser desorption ionization time-of-flight mass spectrometry combined with antimicrobial stewardship in patients with pneumonia and/or bacteremia. Diagn Microbiol Infect Dis. 2016;84(1):63-8.

71. Patel TS, Kaakeh R, Nagel JL, Newton DW, Stevenson JG. Cost analysis of implementing matrix-assisted laser desorption ionization-time of flight mass spectrometry plus real-time antimicrobial stewardship intervention for bloodstream infections. J Clin Microbiol. 2017:55(1):60-7.

72. Messacar K, Hurst AL, Child J, Campbell K, Palmer C, Hamilton S, Dowell E, Robinson CC, Parker SK, Dominguez SR. Clinical impact and provider acceptability of real-time antimicrobial stewardship decision support for rapid diagnostics in children with positive blood culture results. J Pediatric Infect Dis Soc. 2017;6(3):267-74.

73. Bookstaver PB, Nimmich EB, Smith TJ 3rd, Justo JA, Kohn J, Hammer KL, Troficanto C, Albrecht HA, Al-Hasan MN. Cumulative Effect of an Antimicrobial Stewardship and Rapid Diagnostic Testing Bundle on Early Streamlining of Antimicrobial Therapy in Gram-Negative Bloodstream Infections. Antimicrob Agents Chemother. 2017;61:9.

74. Pliakos EE, Andreatos N, Shehadeh F, Ziakas PD, Mylonakis E. The CostEffectiveness of Rapid Diagnostic Testing for the Diagnosis of Bloodstream Infections with or without Antimicrobial Stewardship. Clin Microbiol Rev. 2018:31:3.

75. Luz CF, Berends MS, Dik JH, Lokate M, Pulcini C, Glasner C, Sinha B. Rapid analysis of diagnostic and antimicrobial patterns in $\mathrm{R}$ (RadaR): interactive open-source software app for infection management and antimicrobial stewardship. J Med Internet Res. 2019;21(6):e12843.

76. Lockwood AM, Perez KK, Musick WL, Ikwuagwu JO, Attia E, Fasoranti OO, Cernoch PL, Olsen RJ, Musser JM. Integrating rapid diagnostics and antimicrobial stewardship in two community hospitals improved process measures and antibiotic adjustment time. Infect Control Hosp Epidemiol. 2016;37(4):425-32.

77. Goff DA, Jankowski C, Tenover FC. Using rapid diagnostic tests to optimize antimicrobial selection in antimicrobial stewardship programs. Pharmacotherapy. 2012;32(8):677-87.

78. Hill B, Narayanan N, Palavecino E, Perez KK, Premraj S, Streifel A, Wrenn RH, Zeitler K. The role of an antimicrobial stewardship team in the use of rapid diagnostic testing in acute care: an official position statement of the Society of Infectious Diseases Pharmacists. Infect Control Hosp Epidemiol. 2018; 39(4):473-5.

79. McElvania TeKippe E. The added cost of rapid diagnostic testing and active antimicrobial stewardship: is it worth it? J Clin Microbiol. 2017;55(1):20-3.

80. Wenzler E, Wong JR, Goff DA, Jankowski CA, Bauer KA. Controversies in Antimicrobial Stewardship: Focus on New Rapid Diagnostic Technologies and Antimicrobials. Antibiotics (Basel). 2016;5:1.

81. Timbrook TT, Spivak ES, Hanson KE. Current and future opportunities for rapid diagnostics in antimicrobial stewardship. Med Clin North Am. 2018; 102(5):899-911.

82. Shemanski S, Bennett N, Essmyer C, Kennedy K, Buchanan DM, Warnes A, Boyd S. Centralized Communication of Blood Culture Results Leveraging Antimicrobial Stewardship and Rapid Diagnostics. Open Forum Infect Dis. 2019;6(9):ofz321.

83. Reuter $\mathrm{CH}$, Palac HL, Kociolek LK, Zheng XT, Chao YY, Patel RM, Patel SJ. Ideal and actual impact of rapid diagnostic testing and antibiotic stewardship on antibiotic prescribing and clinical outcomes in children with positive blood cultures. Pediatr Infect Dis J. 2019:38(2):131-7.

84. Sweileh WM. Bibliometric analysis of peer-reviewed literature on climate change and human health with an emphasis on infectious diseases. Glob Health. 2020;16:1.

85. Sweileh WM. Bibliometric analysis of literature in AIDS-related stigma and discrimination. Transl Behav Med. 2019;9(4):617-28.

86. Klein EY, Van Boeckel TP, Martinez EM, Pant S, Gandra S, Levin SA, Goossens $H$, Laxminarayan R. Global increase and geographic convergence in antibiotic consumption between 2000 and 2015. Proc Natl Acad Sci U S A. 2018;115(15):E3463-70.

87. Qu J, Huang Y, LV X. Crisis of antimicrobial resistance in China: now and the future. Front Microbiol. 2019;10:2240.

88. Hu FP, Guo Y, Zhu DM, Wang F, Jiang XF, Xu YC, Zhang XJ, Zhang CX, Ji P, $X i e Y$, et al. Resistance trends among clinical isolates in China reported from CHINET surveillance of bacterial resistance, 2005-2014. Clinical Microbiology Infection. 2016;22(Suppl 1):S9-14. 
89. Xiao Y, Li L. China's national plan to combat antimicrobial resistance. Lancet Infect Dis. 2016;16(11):1216-8.

90. Chan SW. Research collaboration enhances research impact. Int J Nurs Pract. 2015;21(Suppl 2):1.

91. Aldieri L, Kotsemir M, Vinci CP. The impact of research collaboration on academic performance: an empirical analysis for some European countries. Socio Econ Plan Sci. 2018;62:13-30.

92. Aldieri L, Guida G, Kotsemir M, Vinci CP. An investigation of impact of research collaboration on academic performance in Italy. Qual Quant. 2019; 53(4):2003-40.

93. Kunert KJ, Botha AM, Oberholster PJ, Yocgo R, Chimwamurombe P, Vorster J, Foyer $\mathrm{CH}$. Factors facilitating sustainable scientific partnerships between developed and developing countries. Outlook on Agriculture. 2020;49(3):204-14.

94. Zhou P, Cai X, Lyu X. An in-depth analysis of government funding and international collaboration in scientific research. Scientometrics. 2020;125(2): 1331-47.

95. Yam ELY, Hsu LY, Yap EPH, Yeo TW, Lee V, Schlundt J, Lwin MO, Limmathurotsakul D, Jit M, Dedon P, et al. Antimicrobial Resistance in the Asia Pacific region: A meeting report. Antimicrob Resist Infect Control. 2019;8:1.

96. Hijazi K, Joshi C, Gould IM. Challenges and opportunities for antimicrobial stewardship in resource-rich and resource-limited countries. Expert Rev Anti-Infect Ther. 2019;17(8):621-34.

97. Kakkar M, Chatterjee P, Chauhan AS, Grace D, Lindahl J, Beeche A, Jing F, Chotinan S. Antimicrobial resistance in South East Asia: time to ask the right questions. Glob Health Action. 2018:11:1.

98. Bhatia R. Antimicrobial resistance: threat, consequences and options. Natl Med J India. 2018:31(3):133-5.

99. Sakeena MHF, Bennett AA, Carter SJ, AJ ML. A comparative study regarding antibiotic consumption and knowledge of antimicrobial resistance among pharmacy students in Australia and Sri Lanka. PLoS One. 2019;14:3.

100. Chokshi A, Sifri Z, Cennimo D, Horng H. Global contributors to antibiotic resistance. J Global Infect Dis. 2019;11(1):36-42.

101. Amábile-Cuevas CF. Global perspectives of antibiotic resistance. In: Antimicrobial Resistance in Developing Countries; 2010. p. 3-13.

102. Moges F, Endris M, Mulu A, Tessema B, Belyhun Y, Shiferaw Y, Huruy K, Unakal C, Kassu A. The growing challenges of antibacterial drug resistance in Ethiopia. J Global Antimicrobial Resistance. 2014;2(3):148-54.

103. Ayukekbong JA, Ntemgwa M, Atabe AN. The threat of antimicrobial resistance in developing countries: Causes and control strategies. Antimicrob Resist Infect Control. 2017;6:1.

104. Sweileh WM. Global output of research on epidermal parasitic skin diseases from 1967 to 2017. Infect Dis Poverty. 2018;7:1.

105. Sweileh WM. A bibliometric analysis of human strongyloidiasis research (1968 to 2017). Tropical diseases, Travel Medicine and Vaccines. 2019;5:1.

106. Sweileh WM, AbuTaha AS, Sawalha AF, Al-Khalil S, Al-Jabi SW, Zyoud SH: Bibliometric analysis of worldwide publications on multi-, extensively, and totally drug - resistant tuberculosis (2006-2015). Multidisciplinary Respiratory Medicine 2017, 11(1):1-16.

107. (WHO) WHO:World Antibiotic Awareness Week [http://www.euro.who.int/ en/health-topics/disease-prevention/antimicrobial-resistance/worldantibiotic-awareness-week].

108. Y-SA F. G20 summit agrees to take action on antimicrobial resistance. Vet Rec. 2016.

109. Ruano-Ravina A, Álvarez-Dardet C. Evidence-based editing: factors influencing the number of citations in a national journal. Ann Epidemiol. 2012;22(9):649-53.

110. Tahamtan I, Safipour Afshar A, Ahamdzadeh K. Factors affecting number of citations: a comprehensive review of the literature. Scientometrics. 2016; 107(3):1195-225.

111. Xie J, Gong K, Li J, Ke Q, Kang H, Cheng Y. A probe into 66 factors which are possibly associated with the number of citations an article received. Scientometrics. 2019;119(3):1429-54.

112. Abramo G, D'Angelo CA. The relationship between the number of authors of a publication, its citations and the impact factor of the publishing journal: evidence from Italy. Journal of Informetrics. 2015;9(4):746-61.

\section{Publisher's Note}

Springer Nature remains neutral with regard to jurisdictional claims in published maps and institutional affiliations.

\section{Ready to submit your research? Choose BMC and benefit from}

- fast, convenient online submission

- thorough peer review by experienced researchers in your field

- rapid publication on acceptance

- support for research data, including large and complex data types

- gold Open Access which fosters wider collaboration and increased citations

- maximum visibility for your research: over $100 \mathrm{M}$ website views per year

At BMC, research is always in progress.

Learn more biomedcentral.com/submissions 